\title{
ACERCAMIENTO A LA REALIDAD MIGRATORIA DE HUELVA DESDE EL TRABAJO DE CAMPO DEL PROGRAMA DE EXCLUSIÓN DE CÁRITAS DIOCESANA-HUELVA
}

\author{
JUAN J. PERIS MARTÍNEZ \\ Trabajador Social del Programa de Exclusión Social de Cáritas-Huelva.
}

\section{RESUMEN}

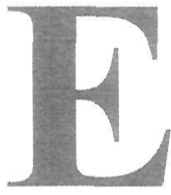

n el sector agrícola de Huelva se ha producido una sustitución de la mano de obra, mediante la realización de los contratos en origen y una categorización de la misma, excluyendo a aquellas personas que tradicionalmente habían realizado el trabajo agrícola. En la periferia de los municipios agrícolas y en los bosques cercanos, se han formado asentamientos de chabolas que constituyen un ejército de mano de obra de reserva en espera de una oportunidad laboral. La discriminación del sector, junto a las condiciones de vida agrícola, ha influido en que un grupo muy específico vea en el trabajo masculino de sexo una estrategia de supervivencia.

El objeto del presente del artículo es aportar la experiencia, y los elementos de conocimiento en ella generados, del trabajo de Cáritas-Huelva con los inmigrantes. Para ello, en el epígrafe II, se analiza su proyecto migratorio; en el III, se describen las condiciones de vida de los inmigrantes en los asentamientos de chabolas; en el IV, se pormenorizan las estrategias de acercamiento e intervención en los asentamientos de chabolas y en las zonas de trabajo de sexo masculino; finalmente, los epígrafes V y VI están dedicados respectivamente a narrar los problemas e irregularidades detectados y a las conclusiones.

Palabras clave: proyecto migratorio, sustitución de mano de obra, categorización de mano de obra.

\section{INTRODUCCIÓN}

En sólo cuatro años, el sector agrícola de Huelva ha pasado de formalizar 600 contratos en origen, principalmente a mujeres procedentes de Polonia, a más de $21.000^{1}$. La población que tradicionalmente realizaba el trabajo en las 
campañas agrícolas se ha visto desplazada y se ha producido una categorización de la mano de obra según su procedencia. A pesar de este fenómeno y de las altas tasas de paro de la población, los inmigrantes siguen llegando a los municipios agrícolas con la certeza de que van a trabajar en la campaña.

En los bosques cercanos y en la periferia de los municipios agrícolas se forman asentamientos de chabolas levantadas por los inmigrantes-documentados e indocumentados- con los plásticos de la fresa, constituyendo un ejército de mano de obra de reserva que espera su oportunidad, bien con los contratos que no son cubiertos con los realizados en origen, o bien trabajando días concretos -festivos, refuerzo en plena campaña, etc.-. La larga espera, la negación sistemática de una oportunidad laboral o las precarias condiciones de vida han influido en que un grupo muy específico haya visto una estrategia de supervivencia en el trabajo masculino de sexo.

La visión que se aporta en el presente trabajo ${ }^{2}$ resulta de la experiencia directa de intervención social que se realiza desde el Programa de Exclusión de Cáritas de Huelva ${ }^{3}$. Por lo tanto, no se aborda aquí un análisis global de la realidad de la inmigración, que constituye un factor de crecimiento de la demografía y un dinamizador de la economía española ${ }^{4}$, ni siquiera se trata de una visión de la inmigración en Huelva, que supondría contemplar tanto la población inmigrante que vive estable en la ciudad como los flujos y condiciones de vida de las personas que llegan con contrato en origen. El objetivo es tan sólo aportar una visión de la realidad de los colectivos inmigrantes más excluidos con los que Cáritas trabaja, de narrar aquéllo que hemos observado, escuchado y después sistematizado, para darlo a conocer a los profesionales y a la comunidad científica.

Los colectivos con los que se ha trabajado están constituidos mayoritariamente por jóvenes varones procedentes del África subsahariana, especialmente Malí; el segundo grupo más importante numéricamente ha sido el de jóvenes varones del Magreb -Marruecos y Argelia-; el tercer grupo, el de personas procedentes de países del Este europeo, principalmente varones jóvenes o de edad intermedia, pero también grupos familiares. Ahora bien, en la elaboración de este estudio, no se analiza la información de todos los inmigrantes indistintamente, salvo en lo que se refiere a relato de las condiciones de vida, donde se recoge información de los tres colectivos. Sin embargo, por su especial relevancia, el relato del proyecto migratorio está construido a partir de la información de las entrevistas realizadas a personas procedentes del África subsahariana, mientras que la información referida a trabajadores masculinos

2 Sin pretender hacerlos responsables de los posibles errores que aquí exponga, muchas de las ideas que guían este escrito han sido tomadas del seminario realizado en la Fundació Migra Studium "Eines per comprendre el fet migratori" coordinado por el profesor Lluís Recolons durante octubre y noviembre de 2005 .

3 La información de las personas entrevistadas ha sido recogida en el trabajo de campo realizado desde el programa de exclusión de Cáritas-Huelva tanto en las zonas de asentamientos humanos de los municipios freseros, como en las zonas de comercio de sexo. También se han realizado entrevistas en profundidad en los diferentes Centros -centros de día y casas de acogida- que integran el programa de exclusión.

4 RECOLONS, LL.: "Las migraciones exteriores en la evolución de la población en España, 1950-2004". Revista de migraciones $\mathrm{n}^{\circ} 17$, Instituto Universitario de Estudios sobre migraciones, Universidad Pontificia de Comillas, Madrid, 2005, pp. $45-89$. 
del sexo se ha extraído de entrevistas a jóvenes marroquíes o de países del Este europeo.

\section{EL PROYECTO MIGRATORIO: DESDE UN CONTINENTE MALTRATADO ${ }^{5}$ HACIA UN SUEÑO EUROPEO}

Las personas dispuestas a iniciar el viaje migratorio desde su país de origen suelen ser aquéllas más fuertes y con mayores recursos personales y sociales. La edad de los que inician el sueño migratorio no suele superar los 25 años. Muchas veces la decisión de emigrar responde a un proyecto familiar de diversificación de riesgos, es decir, la mejor inversión que puede realizar una familia para asegurar su fututo es enviar a un hijo a Europa para poder contar con las remesas de dinero de éste. La responsabilidad suele caer en el primogénito o en el más fuerte. Por otra parte, las remesas de dinero procedentes de los países extranjeros suponen una de las primeras fuentes de ingresos del país.

La decisión de iniciar el viaje hacia Europa es tomada tras valorar detenidamente lo que el individuo percibe que va a ganar o perder. Generalmente, la persona ha probado suerte antes migrando a otros países de la región-migraciones internas-, siendo éstas las migraciones mayoritarias. Además del cálculo de las ganancias, el emigrante cuenta con encontrar "otros bienes públicos", como la ausencia de conflicto y violencia física, cobertura de la sanidad, garantía del imperio de la ley, sistemas de ayuda de ONGs e iglesias, etc., por lo que dar el salto a Europa puede suponer ganar treinta años en esperanza de vida ${ }^{6}$.

A pesar de que los inmigrantes viajan hacia países con unas tasas de paro considerables, saben que trabajarán, ya que la demanda de mano de obra en la economía sumergida es continua y se dirige a cubrir, en determinados sectores, los trabajos menos deseados por la población autóctona. Conforme los trabajadores inmigrantes de la Península van pasando al sector formal, por los procesos de regularización o normalización, los sectores mayoritarios de trabajo de los inmigrantes -construcción, agricultura, servicios- precisan mano de obra para ocupar los puestos que van quedando vacantes en la economía sumergi$\mathrm{da}^{7}$. El mensaje, por tanto, que llega a las personas que pretenden iniciar el proyecto migratorio por parte de los inmigrantes que ya viven en España es "ven, de cualquier manera, que trabajarás". Lo que no les llega a los inmigrantes es "que trabajarán en cualquier cosa" sobreexplotados y en condiciones muy

5 Como, para esta breve descripción del viaje migratorio voy a centrarme en las personas procedentes del África negra, tomo prestado el título de MATEOS, Ó.: "África el continente maltratado", Cuadernos $\mathrm{CiJ} \mathrm{n}^{\circ}$ 137, Cristianisme i Justicia. Barcelona, 2005.

6 RECOLONS, LL., DE SEBASTIÁN, L.: "Economia de la inmigración y mercado de trabajo". Escrito en proceso de publicación.

7 Esta idea de la economía sumergida como causa de la inmigración irregular se repite en varios autores: PAJARES, M.: "Inmigración irregular y mercado laboral: análisis y alternativas" Ponencia mesa 3 del $4^{\circ}$ Congreso sobre la inmigración en España. 2004. PUMARES, P.: "Trabajadores extranjeros en España: evolución y cambios en un contexto de crecimiento económico prolongado (2000-03) Ponencia mesa 3 del $4^{\circ}$ Congreso sobre la inmigración en España. 2004. Sobre inmigración a países con elevadas tasas de desempleo y mercado de trabajo ver también: DE SEBASTIÁN, L: Problemas de la globalización. Cuadernos CiJ $\mathrm{n}^{\circ} 135$, Cristianisme i Justicia, Barcelona, 2005.

8 PAJARES, M.: "Inmigración irregular y mercado laboral: análisis y alternativas". Ponencia mesa 3 del $4^{\circ}$ Congreso sobre la inmigración en España. 2004. 
precarias. Así, la mayoría de personas con las que hemos hablado no se imaginaban que en un país europeo se iban a ver viviendo en chabolas.

Dependiendo de la suerte, de los contactos que se tengan y de las mafias del país de origen o de tránsito, la ruta hacia el país deseado puede ser más o menos larga. En la mayoría de los casos, dura entre un año y medio y dos años. Sin embargo, no llega a destino todo el grupo de salida, ya que el trayecto vuelve a seleccionar a los más fuertes. Las personas que han enfermado o que no resisten el cansancio suelen morir en el trayecto. Tenemos relatos de cómo la persona encargada del grupo, perteneciente a la mafia con la que se ha acordado el viaje, ha acabado con la vida de aquél que no podía soportar el ritmo del grupo. También de cómo, de un grupo de 15 personas, llegaron finalmente a la Península 5 ó 6 . Las grandes dificultades del camino son, sobre todo, el desierto y el soborno para pasar las fronteras de los países de tránsito, siendo usual la violencia física contra las personas, especialmente para conseguir el robo de pertenencias, y la violencia sexual contra las mujeres?.

Por otra parte, el tiempo de espera en los países de tránsito depende también de los conocidos que se tengan en Europa y de los préstamos de dinero que éstos puedan realizar para ir pagando los gastos del viaje y del "salto" a Europa. La espera hasta tener el dinero reunido y poder dar el salto suele tener lugar en campamentos escondidos en el bosque marroquí, en condiciones infrahumanas, donde las mafias organizan los grupos. El que tengan que estar escondidos permanentemente para no ser detectados por la gendarmería dificulta enormemente la labor de ayuda. Finamente, cuando llegan, están totalmente confundidos, ya que, dependiendo de su suerte, país de origen., etc., se enfrentan bien a ser detenidos y deportados bien a que les redacten una orden de expulsión con la comunicación de abandono del país. El inmigrante suele ser atendido primeramente en el CETI (Centro de Estancia Temporal de Inmigrantes), o en el CIE (Centro de Internamiento de Extranjeros), donde se da cobertura a sus necesidades básicas durante un tiempo limitado.

En esta situación y desconociendo tanto el idioma como el entorno, los inmigrantes inician su trayecto por la Península. En la espera en el Norte de Marruecos para dar el salto, han oído hablar del "oro rojo", que es la fresa de Huelva, actividad que precisa de mucha mano de obra en el sector formal, pero también en la economía sumergida.

\section{SUSTITUCIÓN Y CATEGORIZACIÓN DE LA MANO DE OBRA. CONDICIONES DE VIDA DE LOS INMIGRANTES EN PROCESO O RIESGO DE EXCLUSIÓN}

Los sectores en los que trabaja la población inmigrante de los colectivos antes enumerados --jóvenes del Magreb, África subsahariana y Este de Europa-son los segmentos menos deseables ${ }^{10}$, donde suele predominar la economía

9 Sobre el viaje hasta Andalucía, Ceuta y Melilla o Canarias, ver también: Amnistía Internacional: Frontera Sur. Madrid 2005.

10 CACHÓN, L.: "Discriminación y lucha contra la discriminación de los trabajadores inmigrantes" en: CHECA, F.: Inmigración y derechos humanos: la integración como participación social. Icaria, Barcelona, 2004. 
sumergida. En el caso de Huelva, se trata de la agricultura para los varones, y el empleo doméstico en el caso de las mujeres. En 2004, entrevistamos a personas que llevaban más de cinco años en situación de irregularidad administrativa, su estado de cansancio y ansiedad era muy alto.

Los inmigrantes pueden aceptar trabajar por un salario inferior al de los trabajadores nacionales, realizando un mayor número de horas. Es lo que se denomina el salario de reserva: salario por el que estás dispuesto a trabajar ${ }^{11}$. Destacamos en este sentido como un inmigrante recién llegado supone un salario de reserva inferior al de un inmigrante que lleve más tiempo en la Península. Muchos de los entrevistados suelen trabajar de manera discontinua según la necesidad del patrón, especialmente los indocumentados, pero también personas documentadas. Existe un "ejército de mano de obra de reserva" cuya función es la de trabajar de manera discontinua los días que el empresario necesite $^{12}$-festivos, refuerzo en el apogeo de la campaña, etc.--.

El sector agrícola de Huelva ha sufrido en cuatro años una sustitución de mano de obra, al pasar de realizar 600 contratos en origen a realizar $21.000^{13}$. Se ha cambiado del perfil de varones magrebíes por el de mujeres procedentes de países del Este, Polonia principalmente. Los colectivos magrebíes que habían realizado este trabajo en las campañas agrícolas anteriores han sido sustituidos por mujeres del Este a las que se les realiza contrato en origen. Las condiciones de trabajo rechazadas por los trabajadores españoles, sí que son aceptadas por los trabajadores extranjeros.

Existe además una categorización de la mano de obra según su procedencia. La mano de obra no ha sido sustituida sólo por los contratos en origen, existe también una jerarquización marcada por las preferencias de los empresarios a la hora de escoger a sus trabajadores. Estas preferencias han supuesto, en 2004, que la población subsahariana desplazara a la población magrebí, que en años anteriores había sido mayoritaria durante la campaña agrícola. Muchos de los testimonios de las personas magrebíes aseguraban que ese año habían viajado hasta la provincia tras haber contactado con el empresario que les había dado trabajo durante la campaña anterior. A pesar de las expectativas, muy pocos magrebíes trabajaron de forma regular ${ }^{14}$.

En el año 2004, al producirse el desplazamiento de la mano de obra marroquí, gran parte de la población acudió al Centro de Cáritas para personas sin hogar, en busca de los servicios que cubrieran sus necesidades básicas (higiene, ropa, etc.). La saturación del Centro puso en peligro su buen funcionamiento. Ese año, observamos también que gran parte de la población atendida se desplazaba desde los municipios freseros, donde en anteriores campañas agrícolas

11 RECOLONS, LL,; DE SEBASTIÁN, L.: "Economía de la inmigración y mercado de trabajo". Escrito en proceso de publicación.

12 De 4 a 6 dias en 2004. De 10 a 15 días al mes en 2005

13 GUALDA, E.: "Del magrebí a la europea del Este: sustitución de la mano de obra agrícola en la provincia de Huelva" en: Atlas de la inmigración marroqui en España 2004. Taller de estudios Internacionales Mediterráneos. Observatorio permanente de la inmigración. Ministerio de Trabajo y Asuntos Sociales. 2004.

14 Posiblemente, la población subsahariana estaba dispuesta a trabajar "por menos" que la población marroqui, mejor conocedora de las obligaciones del empresario. Por otra parte, los empresarios comentaban que la población subsahariana "cumplia" más y mejor en el trabajo. 
había trabajado, hasta la capital de la provincia en busca de los servicios que cubrieran estas necesidades básicas.

Ante la negación de empleo, comienza la itinerancia por los municipios freseros, en busca de los patronos que les den trabajo. En las entrevistas realizadas, constatamos que caminan una media de 10 kilómetros al día en busca de trabajo. En el caso de las personas indocumentadas, la respuesta es siempre la misma: “tienes papeles?, pues no puedo darte trabajo”. Sin embargo, saben, por sus compañeros que llevan más tiempo en la Península, que, antes o después, el sector agrícola precisará de más mano de obra en la economía sumergida, por lo que la negación continua de "no papeles, no trabajo" es vivida como algo transitorio: "no tengo suerte, Dios lo quiere asi ahora, pero más adelante cambiará...". La espera se suele hacer larga, agravada por el hecho de que las personas inmigradas viven en chabolas de plástico en la periferia de las zonas freseras, muchas veces en situación semiclandestina, para que la guardia civil no los detecte, levante los asentamientos y disperse a la población a su suerte.

Calculamos en unas 1.200 las personas que han vivido en estas condiciones en el $2005^{15}$, aunque este cálculo es difícil de realizar dada la movilidad y la invisibilidad a que estos inmigrantes están sometidos. Mayoritariamente, se trata de varones jóvenes de origen subsahariano que, organizados en grupo, construyen chabolas con los plásticos de la fresa y se alimentan de lo que compran con el salario de los que trabajaban o de lo que recogen a través de la solidaridad de los vecinos, en los contenedores de basura de las grandes superficies o por la ayuda de emergencia de las organizaciones no lucrativas. El desconocimiento del idioma y del entorno, además del miedo a la deportación, limitan su red social, que a menudo queda circunscrita a la relación con las personas procedentes de su mismo origen. En las entrevistas realizadas, hemos comprobado como estos valoraban la ampliación de su red social, -el hecho de conocer a alguien en el municipio, de poder contar con un sitio donde cargar el móvil, o la posibilidad de ayuda en el tema de alquiler de vivienda-, prácticamente tanto o más que la "ayuda de emergencia" que se les hacía llegar desde las organizaciones -comida, ropa, mantas, material de higiene-. Por otra parte, ante la no existencia de estructuras propias a través de las cuales satisfacer sus necesidades, muchos inmigrantes suelen acudir a los centros y servicios destinados para personas sin hogar para cubrir necesidades básicas de higiene, abrigo, etc. ${ }^{16}$.

De esta manera, comienza la ruptura del sueño y la admisión del fracaso del proyecto migratorio. Además de que suelen acarrear deudas del viaje, la familia comienza a interesarse por el envío de remesas de dinero. Entonces, pueden plantearse la obtención de ingresos fuera de la actividad laboral: la

15 Podemos adelantar que han sido unas 400 las personas que habitaban en chabolas durante el 2006 , principalmente en los términos municipales de Lepe, Mazagón y Cartaya - este último minoritario-.

16 El $50 \%$ de las atenciones realizadas desde el Centro de día en el 2004 son a personas procedentes de países extracomunitarios. Un $59^{\circ} 7 \%$ de esta población es magrebi y un $38^{\prime} 2 \%$ es de paises del Este europeo.

En el año 2005 , las atenciones a personas de paises extracomunitarios suponen igualmente un $50 \%$. Los magrebíes conforman el $47^{\prime} 3 \%$ y los ciudadanos de países del Este europeo un $35^{\prime} 5 \%$.

Es destacable en ambos casos la baja asistencia de personas de origen subsahariano que ni siquiera aparecen como grupos mayoritarios de las atenciones realizadas desde el Centro de día. 
mendicidad, el trapicheo, el mercado de sexo. De todas las opciones, la que proporciona dinero "rápido" y queda más oculta ante al resto de la sociedad, $\mathrm{y}$, por lo tanto, tiene menos riesgo de detención y problemas con la justicia, es el trabajo de sexo. La persona puede dar un salto y decidir que va a vivir del trabajo ilegal, o bien combinar éste, como garantía de supervivencia, con la búsqueda de empleo normalizado en la economía sumergida. La situación de indocumentación de estas personas implica una itinerancia por toda la geografía siguiendo las distintas campañas agrícolas y sectores de trabajo en los que predomina la economía sumergida.

A estas dificultades, hay que añadir el alto coste de la vivienda o la renuncia de los propietarios a alquilar viviendas a personas con una identidad etnocultural diferente. Sin una vivienda, no pueden formalizar el empadronamiento en el municipio, imprescindible para acceder a otros servicios como salud o educación de los hijos. Además, quedan condenados a habitar en condiciones de hacinamiento, en locales que no cumplen las condiciones de habitabilidad o en las chabolas de plástico. Por otra parte, el choque cultural se concreta muy gráficamente en el tema de los servicios de salud. El hecho de tener asistencia gratuita universal no garantiza que estén informados o que no tengan miedo, especialmente en las primeras etapas de su estancia, de acceder a los servicios médicos, dado que están indocumentados. Además, las diferencias culturales alimentan la desconfianza en el sistema sanitario. Cuando acuden, salen con la sensación de que el médico no les ha mirado, no les ha tocado, y sospechan que se deba al color de su piel.

Una vez detectados estos problemas, agravados por el desplazamiento de la mano de obra marroquí y la búsqueda de otras estrategias de supervivencia, en 2004, se comienza a realizar trabajo de campo en las zonas de trabajo de sexo masculino. Es en estas zonas también donde se detecta la presencia de menores no acompañados. Los trabajadores del sexo son principalmente jóvenes procedentes del Magreb y de países del Este europeo; por el contrario, las trabajadoras de sexo proceden en su mayoría de Nigeria.

\section{ESTRATEGIAS DE ACERCAMIENTO E INTERVENCIÓN DESDE EL TRABAJO DE CAMPO}

\subsection{Acercamiento a los asentamientos de chabolas de población inmigrante}

Ante esta situación, se comenzó a diseñar el llamado "operativo de emergencia", para atender las necesidades básicas de esta población superior a un millar de personas, progresivamente dispersas, escondidas y alejadas de los núcleos urbanos, debido a que la guardia civil realizaba periódicamente el levantamiento de los asentamientos y la dispersión de quienes allí habitaban. Previamente, se había intentado negociar espacios para montar duchas móviles, a fin de poder garantizar en cada población puntos de referencia para la ayuda. En muchos de los municipios, esta opción fue rechazada bajo el argumento de que se convertiría en un reclamo para otros inmigrantes. En los municipios donde se accedió a instalar este servicio, se ubicó tan lejos del núcleo urbano que los inmigrantes preferían utilizar el agua de riego para el aseo personal. 
Las necesidades más urgentes que pretendíamos cubrir eran: acceso al agua potable -la población bebe del agua de riego y detectamos muchos problemas de gastroenteritis-, acceso a los alimentos -la mayoría de lo que consumían procedía de los contenedores de una gran superficie- y acceso a la sanidad, ya que, aunque ésta estaba garantizada por su universalidad, las diferencias culturales y lingüísticas dificultaban la accesibilidad al servicio.

Dentro del objetivo de intentar cubrir las necesidades básicas de los inmigrantes, se diseñó el operativo humanitario a través del que periódicamente se le haría llegar a la población los alimentos. Se trataba de aprovechar estas visitas para detectar además a las personas enfermas, con el fin de acompañarlas al medico con un traductor, o bien, en los casos más graves, de ofrecerles estancia en la casa de acogida para inmigrantes que tiene Cáritas en Huelva. Con este fin, se planteó la implicación de las Cáritas parroquiales de los municipios agrícolas, organizando el reparto desde las parroquias. Finalmente, se desechó esta alternativa, considerando que, por un lado, no moviliza a la comunidad a salir fuera de ella para encontrarse con el otro y ser consciente de sus condiciones de vida, y, por otro lado, aumenta el imaginario de "invasión, avalancha", al producirse largas colas en la puerta de la iglesia, a la vez que dificulta la idea de inmigración como proceso de integración a medio largo plazo. Cabe pensar que el gran error de esta actuación es haber intervenido con recursos de emergencia en una situación que es estructural y precisa de actuaciones no sólo a corto plazo, con criterios de emergencia, sino también a medio y largo plazo con criterios de integración social.

La estrategia que se siguió entonces fue contactar con los líderes de los grupos, ya que están perfectamente organizados, para hacerles llegar nuestra preocupación por su situación, presentarles lo que somos -no somos empresarios, no somos gobierno- y, desde nuestra realidad y nuestro interés, ofrecerles la posibilidad de un diálogo abierto sobre las posibles formas de ayuda que pudieran requerir. Su respuesta inicial fue rechazar la ayuda alimentaria, aduciendo que sus únicas necesidades eran trabajo y vivienda, que habían pasado en su trayecto por situaciones peores y que sabían que esto es transitorio. Finalmente, el acuerdo alcanzado fue nuestro compromiso de intentar presionar a la Administración y contactar con los empresarios, pero que, mientras tanto, y dado que en ese momento sólo un $40 \%$ del grupo estaba trabajando, traeríamos alimentos para compensar a quienes no estaban trabajando y compartir la aportación solidaria con sus compañeros.

Actualmente, los asentamientos de inmigrantes se visitan periódicamente. Se ha constatado que la suya era parcialmente una situación transitoria, ya que, mientras en el 2004 muchos de los entrevistados no tenían permiso de trabajo, en 2005 se ha producido un crecimiento de los permisos de trabajo y del número de los que están trabajando y perciben ingresos. En las entrevistas realizadas durante noviembre y diciembre del 2005 a los inmigrantes de origen subsahariano, prácticamente todos los documentados coincidieron en que estaban deseando dejar la chabola, que estaban dispuestos a alquilar, pero que nadie -agencias, particulares, Ayuntamiento- les quería alquilar una vivienda.

Por otra parte, en diciembre de 2005, desde la estructura local Caritas de un municipio, se propone que de cara a Navidad se realice un reparto de alimentos 
entre la población que vive en chabolas, y solicita nuestra colaboración para un primer acercamiento. En la visita a los asentamientos, ante esta propuesta, los inmigrantes agradecen nuestra intención, pero aducen que ellos tienen papeles y están trabajando, por lo tanto, compran sus alimentos y proponen que se destinen a quienes acaben de llegar y no tengan ni papeles ni posibilidades de trabajar. Su demanda, sin embargo, se centra en la vivienda, están cansados de intentarlo y nadie quiere formalizar un alquiler.

Actualmente, se está trabajando con las Cáritas parroquiales un modelo de contrato de alquiler por el que el arrendador le alquilaría su propiedad a Cáritas Diocesana, quien a su vez subarrendaría a la población que vive en las chabolas. Con este modelo, Cáritas actúa como valedor de los inmigrantes, garantizando al arrendador que va a percibir puntualmente la renta, además de que el inmueble se le devolverá en perfecto estado. El reto es, por tanto, en estos momentos, abordar el acceso a los servicios básicos, no desde criterios de emergencia, sino estructurales, ya que mientras el motor económico de esos municipios sea la agricultura y los españoles no estemos dispuestos a realizar una serie de trabajos que consideramos menos deseados, serán los inmigrantes quienes estén dispuestos a hacerlo y, por lo tanto, precisaremos de flujos constantes de inmigrantes y de medidas para atenderlos. Además, sabemos que conforme los trabajadores temporeros consiguen contratos más estables, los empresarios precisan del "ejército de reserva" de personas resignadas a trabajar únicamente los días que haya exceso de trabajo y se precisen refuerzos.

Un inconveniente en toda esta situación es que actualmente la realidad migratoria sigue siendo un tema demasiado delicado y sensible para toda la sociedad. El año pasado comprobamos cómo, después del diálogo con la Administración, se producían levantamientos de los asentamientos y la dispersión a su suerte. También pudimos comprobar cómo los levantamientos se producían cuando muchos de ellos buscaban trabajo y no lo encontraban, pero en el momento en que el $90 \%$ de la población estaba trabajando, dejaron de producirse, es más, algunos de ellos regresaron a campamentos iniciales más cercanos a los núcleos urbanos, ya que cada vez que hay un levantamiento lo que hace la población dispersa es montar otro unos kilómetros más alejado y así sucesivamente.

\subsection{Acercamiento a las zonas de trabajo de sexo}

En el año 2004, coincidiendo con el desplazamiento de mano de obra, desde el Centro de día de Cáritas en Huelva, se detectó que algunos de los jóvenes inmigrados comenzaba a obtener pequeños ingresos como trabajadores masculinos del sexo, principalmente se trataba de jóvenes procedentes del Magreb y de países del Este europeo.

Se comenzó un trabajo de aproximación a esta realidad: ver quiénes eran los actores, sus motivaciones, posibles consecuencias, existencia o inexistencia de redes organizadas, utilización o ausencia de medidas de prevención en las relaciones, grado de vulnerabilidad y dependencia, etc. La primera dificultad surgió en el intento de realizar una estimación cuantitativa del fenómeno, ya que muchos de los jóvenes no realizan esta actividad de manera continuada, sino como estrategia de supervivencia mientras encuentran una oportunidad 
en el empleo normalizado. Por otra parte, en las entrevistas, se constató que muchos de ellos recorrían durante el día los municipios freseros en busca de trabajo y, si no lo lograban, acudían por la tarde-noche a las zonas de mercado de sexo masculino de la ciudad. Hubo gente que accedió a trabajar en el sexo a cambio del pago de un billete de autobús y la promesa de ayuda en la búsqueda de empleo. Además, esta actividad es mucho más oculta y menos arriesgada que la delictiva y, por lo tanto, con menos riesgo de ser detectados por la policía, en el caso de las personas sin la documentación necesaria para poder permanecer en el país.

Junto a los que utilizaban esta estrategia de supervivencia de manera transitoria hasta que encontraban un empleo en el trabajo normalizado, se detectó también a los que habían encontrado en esta actividad un modo de obtener dinero rápido, y la posibilidad de vivir por encima de las posibilidades a las que podían haber aspirado trabajando en el mercado normalizado, ya que, muchas veces, los clientes realizaban regalos como ropa de marca, deportivas o móviles de última generación. También había clientes que solicitaban a la persona que les acompañara en algún viaje, donde hotel, copas y tabaco estaban pagados.

Hay que destacar que, en muchos casos, y en mayor medida cuando la actividad se realiza eventualmente sin el aprendizaje que se deriva de la profesionalización, estos jóvenes están sometidos a un alto grado de vulnerabilidad y dependencia, dado que, además, realizan su trabajo en la calle sin ninguna protección. Por otra parte, sorprende el desconocimiento de los riesgos a los que están expuestos por mantener relaciones sin medidas de prevención, así como la falta de información sobre posibles medidas preventivas. Incluso, aquéllos que más conscientes son sobre los riesgos, no dudan en renunciar a la protección a cambio de una retribución adicional.

El mantenimiento del contacto con estos jóvenes, imprescindible para poder trabajar con ellos, no resulta una tarea fácil. Por una parte, se produjeron varias redadas y deportaciones entre las personas que dormían en la calle -y muchas de estas personas dormían en la calle-; por otra parte, aquéllos que no utilizan esta estrategia de forma eventual y se estaban profesionalizando solían trasladarse a Sevilla que, por ser una ciudad mayor, hay mucha más demanda y existes bares específicos de "encuentro" donde las personas van en busca de posibles contactos ${ }^{17}$.

A fin de poder intervenir con esta población, contactamos con Pastoral de la Salud para elaborar unos talleres dirigidos a trabajadores masculinos del sexo, donde se tratara las principales enfermedades de transmisión sexual, las prácticas de riesgo, las formas de prevención, la forma de identificar el contagio, así como dónde acudir a realizar pruebas, diagnóstico y tratamiento en caso de posible infección. A pesar de haber elaborado el material, por las causas que anteriormente hemos expuesto, es difícil el seguimiento de estas personas en

17 Durante marzo y abril de 2005, colaboré con otros colegas en el trabajo de campo en Huelva y Sevilla para la realización de una producción cinematográfica franco-belga sobre estrategias de supervivencia de los extranjeros en Europa ("Le fil rouge"). En el caso de Sevilla, nos centramos en el mercado del sexo; cuando visitamos los "bares de encuentro" encontré personas que conocía por mi trabajo de campo en Huelva en el 2004 y que en aquel año trabajaban en el sexo de forma eventual, por lo que habían dado un salto a hacerlo de forma profesional. 
ciudades como Huelva, dada su alta movilidad, y quizá sea más fácil en ciudades más grandes como Sevilla donde la permanencia temporal parece ser un poco más alta.

Paralelamente a esta realidad, y con los mismos objetivos, se ha realizado trabajo de campo con las mujeres inmigrantes trabajadoras del sexo, principalmente nigerianas. La diferencia esencial respecto a los hombres es que ejercen la actividad de forma más visible y localizada, lo que facilita la posibilidad de que semanalmente se las pueda visitar para conocer sus necesidades. Tanto en el caso de trabajo con los chicos como con las chicas, cabe pensar que algunos de ellos, si atendemos a su apariencia, son menores de edad. Este dato es difícil de comprobar, ya que quienes están en situación irregular suelen esconder su pasaporte para, en caso de detención, dificultar la tarea de identificación, especialmente si se trata de personas procedentes de países con los que España mantiene un acuerdo de devolución en caso de permanencia irregular en territorio español. En cuanto a la edad, también suelen mentir, dependiendo del interés que se tenga en tener una protección especial de la Administración -caso de menores-o querer prescindir de ésta.

Para llegar a saber determinados datos, como la edad o la procedencia, es preciso que el inmigrante confíe en la persona que le pregunta y esto, por lo general, conlleva un tiempo de relación en el que el entrevistador ha de ganarse su confianza. Con los que hemos llegado a tener confianza y a poder hablar abiertamente, hemos constatado que algunos de ellos eran menores que habían estado en centros de protección, pero habían escapado al no ver satisfechas las dos necesidades principales por las que habían dado el salto a Europa: acceso al dinero para enviar a las familias de origen y mayor libertad -no estar sujetos a horarios- por lo que la actividad de la noche les permitía ambas cosas.

\section{PROBLEMAS E IRREGULARIDADES DETECTADAS}

\subsection{Discriminación institucional}

Existe discriminación institucional al existir dificultad administrativa en la tramitación de documentación y en la limitación para trabajar en sectores concretos, que coinciden con los segmentos menos deseados por la población española. Creemos que el hecho de que existan colas diferenciadas en algunas administraciones públicas para población española y extranjera, además de la no existencia de servicios que garanticen la integración de los inmigrantes, dificulta en el imaginario colectivo que veamos al inmigrante como ciudadano, no como excluido.

\subsection{No existencia de perspectiva de género con la mujer inmigrante}

Existe una discriminación de las mujeres inmigrantes en el acceso a determinados recursos especializados: "Las mujeres inmigrantes en situación de residencia irregular no tienen acceso a la red de centros de acogida, sino que son enviadas a centros de atención a inmigrantes, o a albergues municipales 
para indigentes $" 18$. Las mujeres inmigrantes víctimas de violencia de género son percibidas como inmigrantes, no como mujeres que precisan una protección especial. Este mismo informe de Amnistía Internacional recoge relatos de personas que, ante una situación de maltrato, llamaron a la policía y, cuando ésta se personó, se preocupó únicamente por verificar la documentación de la mujer y comprobar en qué situación legal se encontraba. Este hecho dificulta que las mujeres víctimas de violencia decidan dar el paso de denunciar a los maltratadores. Tanto si existe denuncia como si no la hay, y más especialmente en este segundo caso, raramente estas mujeres son derivadas hacia los recursos especializados. Así, al Centro de acogida para personas inmigrantes que tiene Cáritas en Huelva, aunque no es un centro especializado en violencia de género, siguen llegando muchas solicitudes de acogida por parte de otros profesionales dedicados específicamente a la atención a mujeres víctimas de violencia.

\subsection{Deportaciones selectivas.}

Anteriormente, cuando hablábamos del seguimiento en el trabajo de campo con los trabajadores de sexo masculino, decíamos que una dificultad es que, para evitar un alto número de personas durmiendo en la calle, la Subdelegación del Gobierno ordenaba redadas policiales para retornar a posibles personas que estuvieran en situación irregular, a fin de dispersar a la población y limpiar el aspecto de la ciudad -en 2004, estas deportaciones se hicieron en días previos a las fiestas de Navidad y Semana Santa-. Con estas deportaciones selectivas se produjo también la separación de algunos grupos familiares -deportación de un hijo permaneciendo el padre o deportación de un hermano permaneciendo otro hermano-. Algunos familiares de los que habían escapado a la acción policial se dirigían a nosotros preocupados por la suerte que podía haber corrido su familiar.

\subsection{Abusos en el levantamiento de asentamientos y quema de las chabolas.}

Incluso en zonas consideradas "paraje natural", se han producido quemas de chabolas. Los levantamientos se solían producir en torno a las 6 de la mañana. Los inmigrantes eran dispersados a su suerte por la guardia civil. En algunos casos, en los que el levantamiento se ha realizado más tarde y los inmigrantes se encontraban buscando trabajo en la zona, se ha producido también la quema de las pertenencias de los inmigrantes. En zonas concretas, hemos recibido denuncias de abuso de poder por parte de la policía local, al presentarse de madrugada con las sirenas de los coches encendidas y gritando insultos para dispersar a la población. Tras sacar a relucir esta información, no hemos tenido más noticias de levantamientos de asentamientos por parte de la policía local. Las actuaciones las realiza la guardia civil y cuenta con la presencia de la Cruz Roja, que da a cada inmigrante enseres sanitarios antes de dispersarlos a su suerte.

18 AMNISTÍA INTERNACIONAL: Inmigrantes indocumentadas ¿hasta cuándo sin protección frente a la violencia de género?, Madrid, 2005. 


\section{CONCLUSIÓN}

Un rasgo característico de la realidad en la que trabajamos es su extrema movilidad y la necesidad de adaptar las intervenciones a coyunturas siempre cambiantes. Así, por resumir lo más destacable en los tres últimos años, en 2004 se produjo un desplazamiento de mano de obra, por la realización de contratos en origen, que dejó excluidos del mercado laboral a muchísimos magrebíes y ciudadanos de países del Este europeo, que se vieron atrapados en la ciudad e iban a cubrir sus necesidades básicas al centro de personas sin hogar de Cáritas. Ese año se detectó y comenzó el trabajo con jóvenes trabajadores de sexo. 2005 se caracterizó por la menor afluencia de magrebíes, prácticamente toda la población de las chabolas fue subsahariana ${ }^{19}$. En ese año, con 1.200 personas viviendo bajo el plástico, hubo una gran cantidad de levantamientos de asentamientos por parte de la policía y una gran dificultad por parte de los equipos para localizar y hacer llegar la ayuda a las personas que habían sido dispersadas. En 2006, con unas 400 personas viviendo en chabolas, se constata en las entrevistas desde el primer momento de la campaña -especialmente en el municipio de Lepe- que más del $80 \%$ de esta población está trabajando regularmente, muchos de ellos con su situación regularizada tras el último proceso de normalización. El número de levantamientos ha sido muy inferior y la ayuda humanitaria no ha sido tan urgente como otros años. En otros municipios, como Mazagón, donde el trabajo ha sido inferior, los levantamientos y la urgencia de la ayuda humanitaria ha sido similar a la de años anteriores.

Más allá de las situaciones coyunturales, cabe plantear una serie de cuestiones estructurales que deben formar parte de nuestro trabajo: además de garantizar el acceso al agua, alimento, salud, se ha de trabajar para mejorar el acceso a la vivienda y la integración con la población autóctona. Los inmigrantes no deben ser vistos únicamente como mano de obra. Con frecuencia, el rechazo a alquilar viviendas a la población inmigrante radica en los miedos de la población autóctona. Tanto en el caso de que la permanencia de los inmigrantes sea temporal, y más especialmente en el caso de que inmigrantes decidan establecerse en la población, hay que trabajar con la población autóctona para evitar segregación.

La disponibilidad de plazas de estancia temporal para los trabajadores temporeros inmigrantes es claramente insuficiente. El que tengan que acudir a los recursos diseñados para las personas sin hogar dificulta en el imaginario colectivo que los inmigrantes no sean vistos como excluidos, a la vez que agrava la saturación de estos servicios. Además, entre los alojamientos temporales o de emergencia y los alquileres a largo plazo, no existe ninguna fórmula de acceso a la vivienda que contemple situaciones específicas e intermedias.

Una de las dificultades institucionales radica, en el caso de Huelva, en que tenemos una fuerte organización central -diocesana- ubicada en la capital, pero generalmente, las organizaciones locales que tenemos son débiles, y la acumulación de inmigrantes se produce mayoritariamente en los municipios freseros. Esto es, tenemos una fuerte estructura central y dificultades en lo local. Es necesario el fortalecimiento de las estructuras locales. Esta estructura 
local no sólo tiene mucho más poder ante su corporación municipal, sino que es con la que tiene sentido que se cree el vínculo para ver al inmigrante como ciudadano y desde ahí realizar actuaciones de vecindad, como acompañamiento al médico en caso necesario, ayuda para búsqueda de vivienda, etc.

Un aspecto muy importante en la sensibilización es situar el hecho migratorio uniendo el proyecto migratorio de estas personas a la situación que vive su continente y la ausencia de futuro en éste -muy gráficamente en el caso de los subsaharianos-. Hemos de reconocer nuestra parte de responsabilidad tras siglos de expolio, robo, esclavitud y colonialismo en África ${ }^{20}$. Muchas veces proyecto migratorio y drama migratorio van unidos.

A nivel más global, tiene sentido abrir una reflexión conjunta entre los países de origen, los países de tránsito y los países de llegada, para analizar y reflexionar sobre el hecho migratorio y revisar nuestras estrategias y actuaciones, mucho más dado el alto dinamismo que éste tiene. Además, si desde una misma mesa se analiza un mismo fenómeno, se puede apoyar con las acciones de cooperación internacional.

\section{BIBLIOGRAFÍA}

AMNISTÍA INTERNACIONAL: "Inmigrantes indocumentadas ¿hasta cuándo sin protección frente a la violencia de género?", Madrid, 2005.

AMNISTÍA INTERNACIONAL: "Frontera Sur", Madrid, 2005.

CACHÓN, L.: "Discriminación y lucha contra la discriminación de los trabajadores inmigrantes" en: CHECA, F.: Inmigración y derechos humanos: la integración como participación social. Icaria, Barcelona, 2004.

DE SEBASTIÁN, L.: "Problemas de la globalización (comercio, emigración, medio ambiente)". Cuadernos $C J \mathrm{n}^{\circ}$ 135, Cristianisme i Justícia, Barcelona, 2005.

GUALDA, E.: "Del magrebí a la europea del Este: sustitución de la mano de obra agrícola en la provincia de Huelva" en: Atlas de la inmigración marroqui en España 2004. Taller de Estudios Internacionales Mediterráneos. Observatorio permanente de la inmigración. Ministerio de Trabajo y Asuntos Sociales, 2004.

MATEOS, Ó.: “África el continente maltratado”, Cuadernos $C J \mathrm{n}^{\circ}$ 137, Cristianisme i Justícia. Barcelona, 2005

PAJARES, M.: "Inmigración irregular y mercado laboral: análisis y alternativas" Ponencia en la mesa 3 del $4^{\circ}$ Congreso sobre la inmigración en España Ciudadanía y participación, 2004.

PUMARES, P.: "Trabajadores extranjeros en España: evolución y cambios en un contexto de crecimiento económico prolongado (2000-03)". Ponencia en la mesa 3 del $4^{\circ}$ Congreso sobre la inmigración en España Ciudadanía y participación. 2004. Disponible en la web: www.udg. edu/congres_immigracio

RECOLONS, LL.: "Las migraciones exteriores en la evolución de la población en España, 19502004”. Revista Migraciones $\mathrm{n}^{\circ} 17$, Instituto Universitario de Estudios sobre migraciones, Universidad Pontificia de Comillas, Madrid, 2005, pp. $45-89$.

RECOLONS, LL., DE SEBASTIÁN, L.: "Economía de la inmigración y mercado de trabajo". Escrito en proceso de publicación.

20 Sobre este tema y los conflictos armados actuales en África ver: MATEOS, Ó.: "África el continente maltratado", Cuadernos $C J \mathrm{n}^{\circ}$ 137, Cristianisme i Justicia, Barcelona, 2005. 